\title{
Patient-related violence at triage: A qualitative descriptive study
}

\author{
Paper \\ Jacqueline Pich \\ University of Newcastle - School of Nursing \& Midwifery, Callaghan, Newcastle, Australia
}

Keywords: Violence, aggression, nurses, emergency department, workplace, patients

\section{Introduction}

In 1992, the largest number of non-fatal workplace assaults in the United States occurred between nursing staff and patients (Fisher \& Gunnison, 2001). Recent figures estimate that Australian nurses are four times more likely to suffer an assault than those in the general workforce (Hegney, Eley, Plank, Buikstra \& Parker, 2006) and twice as likely to experience work-related crime than other healthcare workers (GallantRoman, 2008). In the United Kingdom the prevalence of episodes of violence from patients is also reported to be escalating (Paniagua, Bond \& Thompson, 2009). The phenomenon of workplace violence has been identified as one of the most complex and dangerous hazards facing the nursing profession today (EstrynBehar, van der Heijden, Camerino, Fry, Le Nezet, Conway \& Hasselhorn, 2008).

Violence in healthcare has been defined as "incidents where staff are abused, threatened or assaulted in circumstances relating to their work...involving an explicit or implicit challenge to their safety, well-being or health" (Mayhew \& Chappell, 2005, p.346). Violence includes verbal abuse, physical threats and assault and emotional abuse (Lyneham, 2000). The specialities of emergency, aged care and mental health nursing have reported the highest prevalence of violence (Estryn-Behar et al, 2008)

Studies have found that violence has become an accepted part of the job for many nurses (Ray, 2007) with verbal and physical abuse regarded as just another occupational hazard (McKinnon \& Cross, 2008). There is widespread acceptance amongst nurses that episodes of violence are unavoidable (Ray, 2007), despite their potentially life-threatening and life-altering nature (Jones \& Lyneham, 2000). It has been suggested that this attitude perpetuates a normalisation of violence, which then becomes embedded in workplace culture (Jackson, Clare \& Mannix, 2002).

The effects of such violence are not only significant physically and psychologically for the nurses involved but represent a heavy financial cost for employers in terms of lost productivity and workers' compensation claims (Lyneham, 2000).

\section{Methods}

This study was conducted in the Emergency Department (ED) of a tertiary referral and teaching hospital in regional New South Wales, Australia. The department regularly records in excess of 5,000 presentations per month.

Six triage nurses were interviewed in August-September 2008 about their experiences with patient-related violence in their workplace during the preceding month. Participants were selected using purposive sampling based on their clinical role (triage) (Streubert \& Carpenter, 1995), and a semi-structured interview schedule was employed. Field notes taken at the time of the interviews were used to augment the transcripts.

Findings were verified with participants to ensure accuracy and validate results. Data were analysed using a qualitative descriptive method to identify emergent themes (Sandelowski, 2000). These findings were discussed with reference to the literature on the subject.

\section{Results}

The analysis of transcribed interviews resulted in identification of several themes described in more detail below.

Patient-related violence was reported by all participants at an average of one episode per day: "I would say it is almost on a daily basis" (participant 2). There was a perception that these episodes were an inevitable part of the job and were increasing in both frequency and intensity: "I think anecdotally it is probably getting worse" (participant 2). 


\section{Physical abuse}

Four participants reported experiencing physical abuse, which resulted in two of them sustaining injuries: "...the next minute he kicked out or hit and just managed to get me in the chest" (participant 4). The types of physical violence experienced included being kicked, slapped and hit by patients and having the safety glass at the triage counter punched. Participants reported being confronted by both traditional and opportunistic weapons including a knife, chair and sharps: “...the knife actually went through the tiny little hole at triage and it came flying in" (participant 4).

\section{Verbal abuse}

All participants reported experiencing verbal abuse with swearing being the most common type. Other forms included threats, shouting, making unreasonable demands, insulting, intimidation, taunting and berating. Participant 2 stated: "Being sworn at - um - people stepping into your personal space - making unreasonable demands- that kind of thing”. Participant 4 spoke of being fearful after her shift "...I have been escorted to my car a few times by security because I was just a bit nervous".

\section{The impact of violent behaviour}

1. Professional. Participants talked about questioning their personal commitment to the job and doubting their professional skills. Many considered moving to what they perceived as a "less stressful" nursing environment or leaving the profession altogether. They also referred to a loss of empathy: "it is hard to be empathetic when someone is abusing you using the fword" (participant 5).

2. Personal. The negative emotions expressed by participants to describe their feelings revealed a sense of powerlessness and hopelessness, for example: "Horrible - absolutely horrible - I feel inside - um degraded" (participant 5).

\section{Antecedents and precipitating factors}

Long waiting times were reported by all participants as a major risk factor for episodes of patient-related violence: "Waiting times. I think that is probably the biggest one" (participant 2). The most significant risk factor reported by participants was high patient volume in the department; particularly the afternoon shift, weekends and during winter. Unrealistic expectations of the workings of the department, especially during periods of peak demand, were also thought to contribute to patient-related violence.

Alcohol and substance misuse were thought to have a significant impact on the likelihood of patients escalating their behaviour and becoming violent: "...alcohol is a big one - we get lots and lots of abuse" (participant 2). Mental health patients were identified as a high risk group due to both the unpredictability of their behaviour and the lack of training and experience of the participants in their management: "none of us...have any mental health training" (participant 5). The majority of participants felt that both males and females were involved in patient-related violence and that females were becoming more aggressive: "we get a lot more fights now with women who have been involved with alcohol...than we used to" (participant 6).

Some nurses were able to recognise cues in patients at risk of escalating to violence and were able to employ de-escalation strategies. Some participants expressed concern that other nurses contributed to episodes of violence: "it is their deliverance and their tone...I can see how people can construe that as being a little bit rude and condescending" (participant 4).

\section{Organisational strategies}

Security guards and duress alarms were identified as the principal employer responses in combating patient-related workplace violence, together with workplace design. For example safety glass built into the triage counter and restricted access to the department.

All participants were aware of the existence of a Zero Tolerance policy towards violence but felt it was ineffective in managing the problem of patient-related violence: "... really what person who has a tendency to become a little agitated is likely to read that sign and say zero tolerance - what does tolerance mean?" (participant 4). Nurses indicated that they were required to cope with such incidents daily in their department notwithstanding the policy on the shelf.

Training such as Aggression Minimisation is a mandatory requirement in New South Wales healthcare; however only three participants had completed partial training: "We don't actually have like formal training with regards to that - no" (participant 1). 


\section{Reporting}

Participants' comments on reporting indicated that the majority of incidents were not reported: "we are supposed to fill it out (reports) but we just don't have the time and it is not user friendly" (participant 5). While participants acknowledged the need for reporting they cited barriers such as: time constraints, lack of response from management, a non-user friendly, lengthy reporting system and the high frequency of violent episodes.

\section{Coping mechanisms}

Informal debriefing with colleagues or family and friends was the method adopted by all participants: "Just debriefing with other people - other staff - looking after them - making sure they are ok - you just laugh it off" (participant 6). Formal debriefing was not offered in relation to violent episodes; however participants felt that it should be mandatory. A workplace culture of accepting violence as part of the job meant that the nurses felt they should be able to cope and get on with the job: "there is that expectationwe should be able to hack it...but that is not the point" (participant 2).

\section{Discussion}

In this study, verbal abuse was reported by all participants with swearing being the most common form of abuse. Up to $82 \%$ of nurses across a range of clinical environments, including the ED, are thought to experience verbal abuse in their workplace (Farrell, Bobrowski \& Bobrowski, 2006). Swearing has been identified as the most widespread and violent form of verbal abuse (Crilly, Chaboyer \& Creedy, 2004; Stone \& Hazelton, 2008).

The types of physical violence detailed by the participants are also reported in the literature. This includes the use of weapons such as knives (Ferns, 2005) and hospital equipment, for example syringes, which are often used against nurses due to their accessibility and availability (Lyneham, 2000; Ferns, 2005). Overt behaviors or symbolic violence designed to intimidate or threaten, such as punching the glass screen at the triage counter, are also discussed (Winstanley \& Whittington, 2004).

Substance abuse and in particular alcohol intoxication have been previously reported to be associated with an increased risk of violent behaviour in patients (Catlette, 2005), and were implicated in over $42 \%$ of all violent episodes in one Australian study (Lyneham, 2000). A causal link has been identified between alcohol use and aggression (Ferns \& Cork, 2008) as it is known to decrease tolerance in frustrating situations (Lyneham, 2000) and incite violent, abusive, threatening and unpredictable behaviour in patients (Ferns, 2005).

Patients with a dual-diagnosis of substance abuse and schizophrenia have been implicated as posing an increased risk of violent behaviour (McKinnon \& Cross, 2008; Duxbury \& Whittington, 2005). Studies have linked serious mental illnesses such as schizophrenia to an increased risk of violence, with sufferers up to two to three times more likely to exhibit violent behaviour than the general population (Friedman, 2006). Lyneham (2000) proposed a link between violent behaviour and lower socio-economic status, which is often linked to other risk factors such as mental health issues and substance abuse (GallantRoman, 2008). Many ED nurses lack mental health nursing experience and skills which has the potential to exacerbate potentially violent situations (Jones \& Lyneham, 2000).

Excessive waiting times are consistently cited as a risk factor for patient-related violence (Pich, Hazelton, Sundin \& Kable, 2010; Jones \& Lyneham, 2000). Other related antecedents include the busy and overcrowded nature of the ED (Hodge \& Marshall, 2007) and a lack of communication on the part of staff (Lau, Magarey ,\& McCutcheon, 2004). Studies have revealed that many patients have unrealistically high expectations of nurses, and when these expectations are not met the resultant anger is usually directed towards nurses (Jackson et al, 2002).

Patient-related violence is more common outside normal working hours (Ferns, 2005), and during the afternoon shift (1500-2300) (approximately 40 percent of all assaults) (Dalphond, Gessner, Giblin, Hijazzi $\&$ Love, 2000), which is consistent with the findings of this study.

Verbal abuse has been associated with long lasting psychological reactions (Gerberich, Church, McGovern, Hansen, Nachreiner, Geisser, Ryan, Mongin, \& Watt, 2004). These range from feelings of guilt and selfdoubt, (Arnetz \& Arnetz, 2001); to anger and powerlessness, (Astrom, Karlsson, Sandvide, Bucht, Eisemann, Norberg, \& Saveman, 2004); and post traumatic stress disorder (Camerino, Estryn-Behar, Conway, van Der Heijden, \& Hasselhorn, 2008). Despite this, informal debriefing with colleagues was the most common coping mechanism referred to in the literature (Astrom et al, 2004). 
A lack of debriefing services offered by employers is highlighted in the literature; with nurses expressing the belief that debriefing after stressful incidents should be mandatory rather than optional and be conducted by professionals in the area (Ross-Adjie, Leslie \& Gillman, 2007). An Australian study of ED nurses found that $52 \%$ were never offered support by management following a significant episode of violence (Lyneham, 2000).

Access to the ED has been identified as a major source of concern for nurses (Catlette, 2005) due to its accessibility to the general public (Phillips, 2007). In response security provisions such as increased personnel, the use of duress alarms together with workplace design features such as restricted access and security cameras have been advocated (May \& Grubbs, 2002).

Lack of action by management is consistently reported in the literature as a reason for the under-reporting of episodes of patient-related violence in all clinical settings (Gallant-Roman, 2008). Nurses should be encouraged to report all violent incidents so that an accurate picture of the problem can be created to guide policy development in this area (Lyneham, 2000).

Training is frequently claimed to be an effective management tool in combating workplace violence, and is mandatory in New South Wales (NSW Health, 2005). However nurses are still not adequately trained (Lyneham, 2000). The nature of triage nursing means that the nurses' communication skills and coping mechanisms are vital for the prevention and de-escalation of violence (Jones \& Lyneham, 2000).

\section{Conclusion}

It is evident that patient-related violence at triage is a reality for ED nurses in their everyday working lives; however this is an unacceptable hazard in their workplace. A major issue appears to be the lack of commitment on the part of employers: firstly to acknowledge the magnitude and seriousness of the issue and secondly to adopt preventive and supportive strategies to manage it. While patient-related violence may not be totally eliminated in the ED, it can be reduced so that ED nurses are working in a safer working environment as mandated under Occupational Health and Safety legislation (Pich et al, 2010).

\section{References}

Arnetz, J. E., \& Arnetz, B. B. (2001). Violence towards health care staff and possible effects on the quality of patient care. Social Science and Medicine, 52(3), 417-427.

Astrom, S., Karlsson, S., Sandvide, A., Bucht, G., Eisemann, M., Norberg, A., \& Saveman, B.I. (2004). Staff's experience of and the management of violent incidents in elderly care. Scandinavian Journal of Caring Sciences, 18(4), 410-416.

Camerino, D., Estryn-Behar, M., Conway, P. M., van Der Heijden, B. I., \& Hasselhorn, H. M. (2008). Work-related factors and violence among nursing staff in the European NEXT study: a longitudinal cohort study. International Journal of Nursing Studies, 45(1), 35-50.

Catlette, M. (2005). A descriptive study of the perceptions of workplace violence and safety strategies of nurses working in level I trauma centers. Journal of Emergency Nursing, 31(6), 519-525.

Crilly, J., Chaboyer, W., \& Creedy, D. (2004). Violence towards ED nurses by patients. Accident and Emergency Nursing, 12(2), 67-73.

Dalphond, D., Gessner, M., Giblin, E., Hijazzi, K. \& Love, C. (2000). Violence against emergency nurses. Journal of Emergency Nursing, 26(2), 105-111.

Donnelly, C. (2006). Tackling violence head on. Emergency Nurse, 13(10), 5.

Duxbury, J., \& Whittington, R. (2005). Causes and management of patient aggression and violence: staff and patient perspectives. Journal of Advanced Nursing, 50(5), 469-478.

Estryn-Behar, M., van der Heijden, B., Camerino, D., Fry, C., Le Nezet, O., Conway, P. M. \& Hasselhorn, H.M. (2008). Violence risks in nursing--results from the European 'NEXT' Study. Occupational Medicine, 58(2), 107-114.

Farrell, G. A., Bobrowski, C., \& Bobrowski, P. (2006). Scoping workplace aggression in nursing: findings from an Australian study. Journal of Advanced Nursing, 55(6), 778-787.

Ferns, T. (2005a). Terminology, stereotypes and aggressive dynamics in the accident and ED. Accident and Emergency Nursing, 13(4), 238-246.

Ferns, T. \& Cork, A. (2008). Managing alcohol related aggression in the emergency department (part I). International Emergency Nursing, 16(1), 43-47.

Fisher, B. S. \& Gunnison, E. (2001). Violence in the workplace: Gender similarities and differences. Journal of Criminal Justice, 29(2), 145-155.

Friedman, R. A. (2006). Violence and mental illness--how strong is the link? New England Journal of Medicine, 355(20), 2064-2066.

Gallant-Roman, M.A. (2008). Strategies and tools to reduce workplace violence. AAOHN Journal, 56(11), 449-454.

Gerberich, S. G., Church, T. R., McGovern, P. M., Hansen, H. E., Nachreiner, N. M., Geisser, M. S., Ryan, A.D., Mongin, S.J., \& Watt, G.D. (2004). An epidemiological study of the magnitude and consequences of work related violence: the Minnesota Nurses' Study. Occupational and Environmental Medicine, 61(6), 495-503.

Hegney, D., Eley, R., Plank, A., Buikstra, E., \& Parker, V. (2006). Workplace violence in Queensland, Australia: the results of a comparative study. International Journal of Nursing Practice, 12(4), 220-231. 
Hodge, A. N., \& Marshall, A. P. (2007). Violence and aggression in the emergency department: A critical care perspective. Australian Critical Care. 20(2), 61-67.

Jackson, D., Clare, J., \& Mannix, J. (2002). Who would want to be a nurse? Violence in the workplace--a factor in recruitment and retention. Journal of Nursing Management, 10(1), 13-20.

Jones, J., \& Lyneham, J. (2000). Violence: part of the job for Australian nurses? Australian Journal of Advanced Nursing, 18(2), 27-32.

Lau, J., Magarey, J. \& McCutcheon, H. (2004). Violence in the ED: A literature review. Australasian Emergency Nursing Journal, 7(2), 27-37.

Lyneham, J. (2000). Violence in New South Wales EDs. Australian Journal of Advanced Nursing, 18(2), 8-17.

May, D. D., \& Grubbs, L. M. (2002). The extent, nature, and precipitating factors of nurse assault among three groups of RNs in a regional medical center. Journal of Emergency Nursing, 28(1), 11-17.

Mayhew, C. \& Chappell, D. (2005). Violence in the workplace. The Medical Journal of Australia, 183(7), 346-347.

McKinnon, B., \& Cross, W. (2008). Occupational violence and assault in mental health nursing: a scoping project for a Victorian Mental Health Service. International Journal of Mental Health Nursing, 17(1), 9-17.

NSW Health. (2005). Training program - a safer place to work: Preventing/managing violent behaviour - NSW Health. NSW Department of health: North Sydney, NSW.

Paniagua, H., Bond, P., \& Thompson, A. (2009). Providing an alternative to zero tolerance policies. British Journal of Nursing, 18(10), 619-623.

Phillips, S. (2007). Countering workplace aggression: an urban tertiary care institutional exemplar. Nursing Administration Quarterly, 31(3), 209-218.

Pich, J.V., Hazelton, M., Sundin, D. \& Kable, A. (2010) A. Patient-related violence at triage: A qualitative descriptive study. International Emergency Nursing, doi: 10.1016/j.ienj.2009.11.007.

Ray, M. M. (2007). The dark side of the job: violence in the ED. Journal of Emergency Nursing, 33(3), 257-261.

Ross-Adjie, G. M., Leslie, G. \& Gillman, L. (2007). Occupational stressor in the ED: What matters to nurses? Australasian Emergency Nursing Journal, 10(3), 117-123.

Sandelowski, M. (2000). Whatever happened to qualitative description? Research in Nursing \& Health, 23(4), 334-340.

Stone, T. E. \& Hazelton, M.(2008) An overview of swearing and its impact on mental health nursing practice. International Journal of Mental Health Nursing, 17(), 208-214.

Streubert, H.J. \& Carpenter, D.R. (1995). Qualitative research in nursing. Philadelphia, PA: J. B. Lippincott Co.

Winstanley, S., \& Whittington, R. (2004). Aggression towards health care staff in a UK general hospital: variation among professions and departments. Journal of Clinical Nursing, 13(1), 3-10.

\section{Educational goals}

1. To gain an Australian perspective on a global issue facing nurses, that of patient-related workplace violence.

2. To be able to recognise some of the common precipitating and causal factors of episodes of patientrelated violence identified in this study that are consistent with literature.

\section{Correspondence}

Mrs Jacqueline Pich

University of Newcastle - School of Nursing \& Midwifery

University Drive

2301

Callaghan, Newcastle

Australia

+61249215768

Jacqueline.Pich@newcastle.edu.au 